\title{
A Differential Pressure Technique for Void Fraction Measurement in Gas-Liquid Flow
}

\author{
Ammar ZEGHLOUL, Abdelwahid AZZI, Nabil GHENDOUR, and Abdallah S. BERROUK
}

\begin{abstract}
Two-phase Gas-liquid flows have many industrial uses, such as hydrocarbon transportation and energy production. The knowledge and an accurate determination of the gas phase's proportion rate in the two-phase mixture known as the gas void fraction is necessary for optimal and secure sizing of the installations where this kind of flow takes place. This paper focuses on the possibility of using a cost-effective differential pressure transmitter to measure the void fraction parameter. It is obtained using a mathematical model derived from the energy balance equation and the measured pressure drop from the vertical upward gas-liquid flow. Results on flow void fraction obtained through the use of the conductance probe method, are used to validate those derived from the pressure drop that is evaluated by employing the differential pressure transmitter. The measurement accuracy of the void fraction measured using the pressure drop technique, is found to be principally affected by the flow pattern. Moreover, the slip ratio between the phases was the primary factor influencing the void fraction measurement by the differential pressure technique.
\end{abstract}

Keywords- Two-phase flow, Void fraction, Flow pattern, Differential pressure, Transmitter.

NOMENCLATURE

\begin{tabular}{|l|l|}
\hline $\mathrm{D}$ & Diameter of the pipe, $\mathrm{m}$ \\
\hline$f$ & Single-phase friction factor \\
\hline $\mathrm{g}$ & Acceleration of gravity, $\mathrm{m} / \mathrm{s}^{2}$ \\
\hline $\mathrm{h}$ & Pressure tapping vertical distance, $\mathrm{m}$ \\
\hline $\mathrm{P}$ & Pressure at the taping, Pa \\
\hline $\mathrm{Re}$ & Reynolds numbers \\
\hline $\mathrm{S}$ & Slip ratio \\
\hline $\mathrm{U}_{\mathrm{m}}$ & Mixture velocity, $\mathrm{m} / \mathrm{s}$ \\
\hline $\mathrm{U}_{\mathrm{G}}$ & Gas velocity, $\mathrm{m} / \mathrm{s}$ \\
\hline $\mathrm{U}_{\mathrm{GS}}$ & Gas superficial velocity, $\mathrm{m} / \mathrm{s}$ \\
\hline $\mathrm{U}_{\mathrm{L}}$ & Liquid velocity, $\mathrm{m} / \mathrm{s}$ \\
\hline $\mathrm{U}_{\mathrm{LS}}$ & Liquid superficial velocity, $\mathrm{m} / \mathrm{s}$ \\
\hline$x$ & Mass flow quality \\
\hline$\varepsilon_{\mathrm{G}}$ & Gas void fraction \\
\hline$\Delta \mathrm{P}$ & Pressure drop, Pa \\
\hline$\rho_{\mathrm{L}}$ & Liquid density, $\mathrm{kg} / \mathrm{m}^{3}$ \\
\hline$\rho_{\mathrm{G}}$ & Gas density, $\mathrm{kg} / \mathrm{m}^{3}$ \\
\hline$\rho_{\mathrm{TP}}$ & Two-phase mixture density, $\mathrm{kg} / \mathrm{m}^{3}$ \\
\hline $\mathrm{G}$ & Gas \\
\hline $\mathrm{L}$ & liquid \\
\hline$m$ & mixture \\
\hline$T P$ & two-phase flow \\
\hline
\end{tabular}

Manuscript received October 4, 2021; revised December 26, 2021. A. Zeghloul is with the University of Sciences and Technology Houari Boumediene and the Ecole Nationale Polytechnique, Algiers, Algeria. (e-mail: ammar.zeghloul@g.enp.edu.dz)

A. Azzi is with the University of Sciences and Technology Houari Boumediene, Algiers, ALGERIA. (e-mail: azzi.1963@yahoo.fr)

N. GHENDOUR is with the University of Sciences and Technology Houari Boumediene, Algiers, ALGERIA (e-mail: ghendour.nabil@gmail.com)

A. S. BERROUK is with Khalifa University of Science and Technology, Abu Dhabi, United Arab Emirates. (e-mail: abdallah.berrouk@ku.ac.ae)

Digital Object Identifier (DOI): 10.53907/enpesj.v1i2.21.61

\section{INTRODUCTION}

In two-phase or three-phase flow hydrodynamics, the void fraction represents one of the most critical parameters. It gives information about the fraction of the gas in the pipe's total surface or volume. Moreover, the void fraction is a crucial parameter in predicting the interfacial section and the masse transfer between different phases [1].

Several invasive or non-invasive techniques have been proposed in the literature to predict the void fraction parameter. Among these techniques, one can cite the estimation of void fraction via the time-averaged two-phase pressure drop measurement. This technique is widely used because of its simplicity, high safety, low-cost, and for being non-intrusive. Additionally, the two-phase pressure acquisition signals can be used in two-phase flow pattern recognition [2][3].

Many works have been done in order to establish a correlation between the void fraction and the measured two-phase pressure drop. However, these correlations were not reliable for all flow patterns. In the earlier work, Wallis [4] correlates the liquid holdup $\left(1-\varepsilon_{\mathrm{g}}\right)$ as a function of Lockhart and Martinelli's parameter, which depends on the two-phase pressure drop. Tang and Heindel [5] proposed a new method to estimate the void fraction from the differential pressure measurement in bubble columns. The proposed method highlighted the pressure drop's influence due to friction on the void fraction measurement. Their experimental data analysis showed that the proposed method gives more accurate void fraction results than the model proposed by Wallis. As Gharat and Joshi [2] stated, the frictional two-phase pressure drop depends mainly on two factors. One of them depends on the shear stress between the liquid and the conduit wall, and the second is the friction between the liquid and the gas phases. On the other hand, the experimental work presented by Shafquet et al. [6] considered the frictional parameter negligible . In their study, the tested flow condition covered the bubbly flow pattern with the range of the void fraction [0.17 to 0.33]. They used Electrical Capacitance Tomography technique, ECT, as another technique to validate the void fraction predicted results. Abbas [7] performed a theoretical and experimental study for the bubbly flow regime, considering the value of the void fraction 
less than 0.1748 . They proposed a mathematical model derived from the two-phase pressure drop measurement to estimate the gas proportion. However, the experimental results showed that the proposed model is not suitable when the void fraction increases beyond $17.48 \%$. Jia et al. [8] conducted an experimental study in vertical upward bubbly and slug flows. To obtain the void fraction, two-phase pressure drop measurement data were introduced into a mathematical model that was based on the energy conservation. The latter was compared to the ones obtained from Electrical Resistance Tomography, ERT, device and Wire Mesh Sensor, WMS. The experimental investigations showed that the frictional pressure drop could not be neglected mostly for a gas volume fraction less than 0.2. Kara et al. [9] performed a comparison of the void fraction values derived from the pressure drop experimental data and those by measuring the difference in the level between the two-phase mixture and the one of the static liquid in a bubble column. They found that both measurement technics matched well with an accuracy of $3 \%$.

The present experimental study consists in investigating the derivation of the void fraction using differential pressure measurement. Moreover, the effect of the flow pattern on the void fraction measurement accuracy is discussed.

\section{THEORETICAL BACKGROUND}

The mathematical correlation relying the void fraction and differential pressure measurement is based on Bernoulli's energy conservation principle. According to the diagram in Figure 1. One can write;

$$
\mathrm{P}_{1}=\mathrm{P}_{2}+\rho_{\mathrm{TP}} \mathrm{gh}+\Delta \mathrm{P}_{\text {friction }}
$$

where $P_{1}$ and $P_{2}$ are the measured pressures at two selected positions along the pipe, $\rho_{\text {TP }}$ is the two-phase density, $g$ is the gravitational acceleration, $h$ is the distance between the two measurement points and $\Delta \mathrm{P}_{\text {friction }}$ the frictional pressure drop.

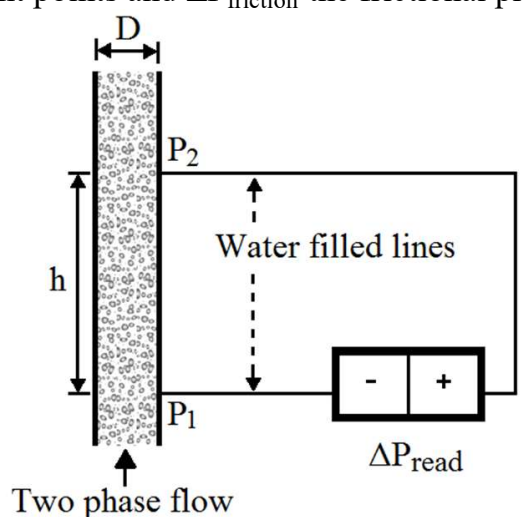

Fig. 1: Void fraction measurement

Measured pressure drop (read) between the two tappings, $\Delta \mathrm{P}_{\text {read }}$, can be expressed from the hydrodynamic balance as;

$$
\Delta \mathrm{P}_{\text {read }}=\mathrm{P}_{2}+\rho_{\mathrm{L}} \mathrm{gh}-\mathrm{P}_{1}
$$

Eq. 1 and Eq. 2 lead to;

$$
\Delta \mathrm{P}_{\text {read }}+\Delta \mathrm{P}_{\text {friction }}=\mathrm{gh}\left(\rho_{\mathrm{L}}-\rho_{\mathrm{TP}}\right)
$$

The two-phase density $\rho_{\mathrm{TP}}$ is expressed as follow:

$$
\rho_{\mathrm{TP}}=\varepsilon_{\mathrm{G}} \rho_{\mathrm{G}}+\left(1-\varepsilon_{\mathrm{G}}\right) \rho_{\mathrm{L}} \approx\left(1-\varepsilon_{\mathrm{G}}\right) \rho_{\mathrm{L}}
$$

where $\varepsilon_{\mathrm{G}}$ is the void fraction.

Replace Eq. 4 into Eq. 3 and solving for void fraction $\varepsilon_{\mathrm{G}}$ reads:

$$
\varepsilon_{\mathrm{G}}=\frac{\left(\Delta \mathrm{P}_{\text {read }}+\Delta \mathrm{P}_{\text {friction }}\right)}{\left(\rho_{\mathrm{L}}-\rho_{\mathrm{G}}\right) \mathrm{g} \mathrm{h}}
$$

According to [7], the pressure drop due to friction is:

$$
\Delta \mathrm{P}_{\text {friction }}=\frac{2 \rho_{\mathrm{L}} \mathrm{h} f \mathrm{U}_{\mathrm{m}}^{2}}{\mathrm{D}}
$$

Where $U_{m}$ represents the mixture velocity, $D$ is the internal pipe diameter, and $f$ the single-phase friction factor, also known as the Fanning friction factor, which depends on flow conditions and the pipe wall roughness. In our experiment, the pipe material is Perspex, which can be considered a smooth surface.

The friction factor, $f$, can be obtained experimentally by employing the following expression [7];

$$
f=\frac{\Delta \mathrm{P}_{\mathrm{L}} \mathrm{D}}{2 \rho_{\mathrm{L}} \mathrm{h} \mathrm{\textrm {U } _ { \mathrm { L } } ^ { 2 }}}
$$

Where $\Delta \mathrm{P}_{\mathrm{L}}$ is the measured liquid pressure drop, and $\mathrm{U}_{\mathrm{L}}$ is the liquid velocity.

A different form of Fanning friction factor can be found in the literature, which depends on Reynolds numbers, Re. In the present work, the Reynolds numbers test conditions were ranged from 3500 to 30600. The corresponding Fanning friction factor $f$ is expressed as;

$$
f=0.079 \mathrm{Re}^{-0.25}
$$

\section{EXPERIMENTAL FACILITY}

The test facility performed to carried out measurements of the pressure drop and the void fraction simultaneously is presented in Figure 2. This test facility has been used earlier by Zeghloul et al.[10][11]. The test section, which is transparent for visual observation of the flow regime is positioned vertically. Its length is about $6 \mathrm{~m}$ with an inner diameter of $34 \mathrm{~mm}$. A centrifugal pump (9), which can reach a maximal masse flow rate of $40 \mathrm{~m}^{3} / \mathrm{s}$, draws tap water from the tank (10) to the mixing section through calibrated water rotameters (4). A pressure regulator (2) was used to adjust the air supplied from a compressor (1) to the operating pressure before it passes through the air rotameters (5). Both air and water flow-meters have a maximum uncertainty of $2 \%$. The two-phases are blended in the mixer (8) to create the air-water mixture. Further information on the mixer geometry is given in Zeghloul et al. [12], [13]. After the mixer, the gas and liquid phases flow through the test section then continues up to the separator (10). The liquid flowed down to the separator's bottom due to gravity, and the gas (air) flows into the ambient.

Two conductance probes have been installed in the vertical test section to provide the gas volume fraction, $\varepsilon_{\mathrm{G}}$. The first conductance probe, CP1, was placed at $4760 \mathrm{~mm}$ (140D) downstream of the mixer, and the second probe, CP2, at a distance of $790 \mathrm{~mm}$ after the first probe. These two positions were chosen carefully to ensure enough distance to allow the flow to be fully developed Saidj et al. [14]. 
To increase the measurement accuracy, two selected differential pressure transmitters have been used to measure the difference in pressure between the two tappings. The latter has the exact locations as the two conductance probes CP1 et CP2. The two transmitters were provided from FOXBORO company with $0.2 \%$ accuracy corresponding to their full scale with ranges of [0-7.2] $\mathrm{kPa}$ and [0-36] $\mathrm{kPa}$, respectively. Using an appropriate pressure calibrator (Fluke 725) with an error of $0.02 \%$, the two transmitters were further re-calibrated.

Before starting the pressure measurements, it is necessary to ensure that the pressure sampling lines have a constant fluid density, i.e., the pressure lines contain only liquid without any air bubbles inside. Therefore, a purging arrangement has been used to evacuate air bubbles from the pressure sampling lines, as shown in Figure 3.

A data acquisition card (6092E) and the corresponding LabVIEW software from National Instruments Company, was used to acquire all the necessary data from the different experiments. $200 \mathrm{~Hz}$ was the sampling frequency of the data acquisition for a duration of 60 seconds for each test, i.e., total data samples of 12000 for each run.

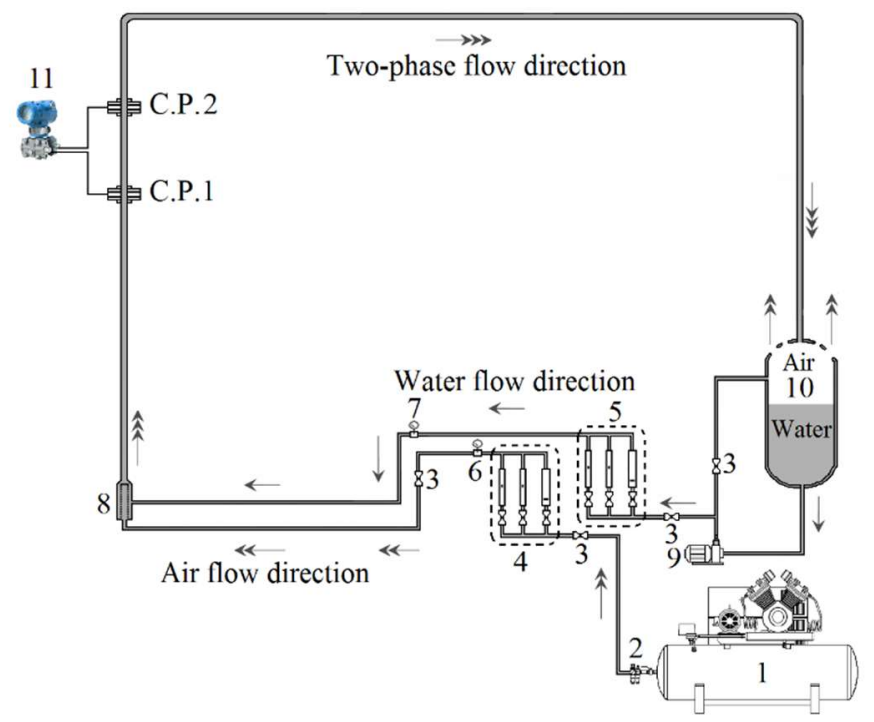

1: Compressor, 2: regulator, 3: Valve, 4: Air Flow-meters, 5: Water flow-meters, 6: Manometer, 7: Thermometer, 8: Mixer, 9: Pump,

10: Tank/Separator, 11: Differential pressure transmitter, CP1-CP2: Conductance probes

Fig. 1: Test facility.

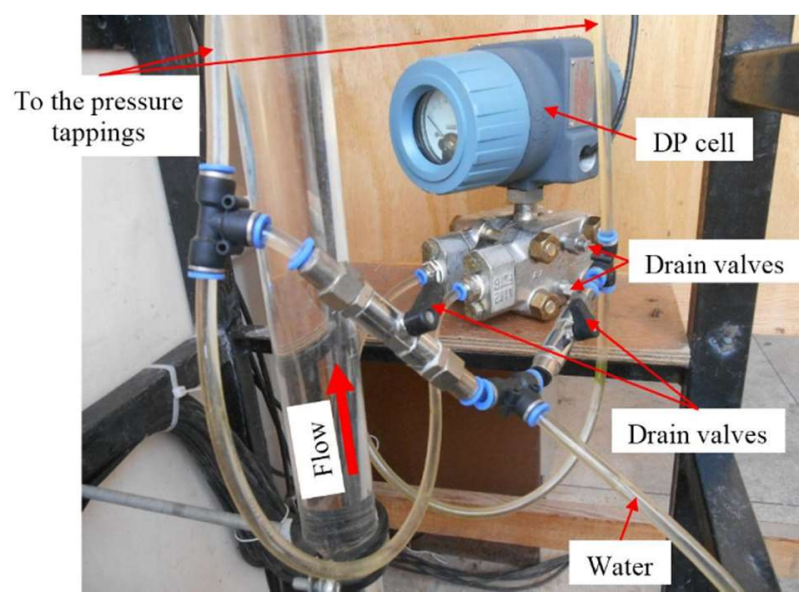

Fig. 2: Purging system arrangement [15].

\section{IV.EXPERIMENTAL RESULTS}

\section{A. Flow Pattern Map}

The test experimental conditions of the gas and liquid superficial velocities varied from 0 to $3.5 \mathrm{~ms}^{-1}$ and from 0.1 to $0.92 \mathrm{~ms}^{-1}$, respectively, which cover a wide flow pattern range from bubbly to churn flows. The two-phase flow configuration was first visually observed through the Plexiglas pipes near the pressure tapings. At these locations, the flow regime is considered to be entirely developed. These flow observations were confirmed by analyzing the signature shape of the Probability Density Function (PDF) and the temporal variation of the acquired gas volume fraction signals (Bouyahiaoui et al. [16], Costigan and Whalley[17]).

The test experimental conditions of the gas and liquid superficial velocities varied from 0 to $3.5 \mathrm{~ms}^{-1}$ and from 0.1 to $0.92 \mathrm{~ms}^{-1}$, respectively, which cover a wide flow pattern range from bubbly to churn flows. The two-phase flow configuration was first visually observed through the Plexiglas pipes near the pressure tapings. At these locations, the flow regime is considered to be entirely developed. These flow observations were confirmed by analyzing the signature shape of the Probability Density Function (PDF) and the temporal variation of the acquired gas volume fraction signals (Bouyahiaoui et al. [16], Costigan and Whalley[17]).

From Figure 4, A total number of 121 experimental test conditions were plotted over the flow pattern map of Shoham [18]. From this figure, one can note that the slug flow test conditions have taken a large area in Shoham's map. Furthermore, the transition line between the bubbly and the slug flow shows a good prediction of the experimental test conditions. However, the slug/churn line transition poorly predicts the experimental data. This overprediction may be due to the difference in the experimental conditions used in predicting the slug/churn line transition.

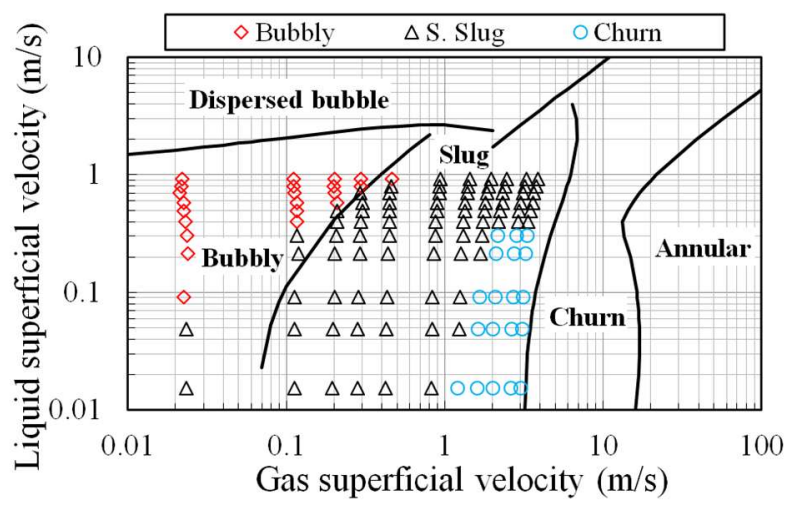

Fig. 3: Shoham's flow pattern map [18] including the experimental test conditions studied in the present work.

\section{B. Void Fraction Temporal Variation}

Figure 5 illustrates example plots of the void fraction temporal variation obtained from the two conductance probes (CP1 and CP2). Three different velocities combination of liquid and gas has been chosen to exhibit the various flow patterns studied in this work. It can be observed from the void fraction temporal variation that the two conductance probe signals are very close to each other, which confirms that the flow pattern is thoroughly 
developed [14]. Figure 5 (a) shows the typical void fraction signal of bubbly flow. The latter is often characterized by stable fluctuations with some small peaks that indicate both agglomerated and dispersed bubbles. The mean void fraction of the corresponding bubbly flow is about 0.19 . Figure 5 (b) depicts the slug flow void fraction temporal variation that was represented by an alternative value of the void fraction. The void fraction values of the threshold corresponding to the passage of Taylor bubbles, and the low void fraction values representing the liquid plug, which contain tiny bubbles. The mean void fraction value of the corresponding slug flow is found to be 0.45 . Figure 5 (c) represents a typical void fraction temporal variation of the churn flow. This flow pattern signals and appearance show a chaotic behavior with a mean void fraction of 0.81 .

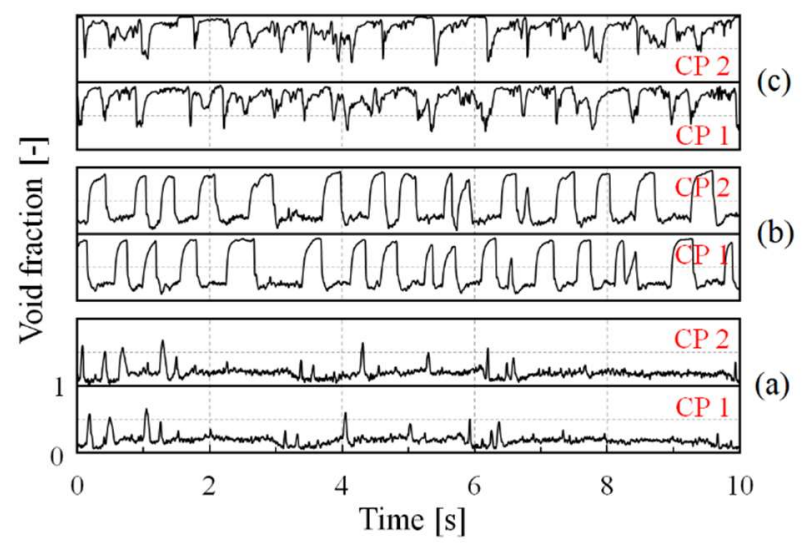

Figure 4: Temporal variation of the void fraction, (a), bubbly flow [Uls $=0.80 \mathrm{~m} \cdot \mathrm{s}^{-1}, \mathrm{Ugs}=0.10 \mathrm{~m} \cdot \mathrm{s}^{-1}$ ], (b), slug flow [Uls $=0.40$ $\mathrm{m} . \mathrm{s}^{-1}, \mathrm{Ugs}=0.43 \mathrm{~m} \cdot \mathrm{s}^{-1}$, (c), churn flow [Uls $=0.21 \mathrm{~m} . \mathrm{s}^{-1}$, $\mathrm{Ugs}=3.01 \mathrm{~m} \cdot \mathrm{s}^{-1}$,

\section{C. $\quad$ Single and Two-Phase Flow Pressure Drop}

The measured two-phase gas-liquid pressure drop, $\Delta \mathrm{P}_{\text {read }}$, from the differential pressure transmitter was fed into the equation (2) to obtain the total pressure difference $\left(P_{1}-P_{2}\right)$. Figure 6 represents the gas-liquid total pressure drop variation depending on the gas superficial velocity by keeping the liquid superficial velocity constant. From this figure, one can see for a particular gas superficial velocity that the gas-liquid total pressure drop increases with the liquid superficial velocity's augmentation. Furthermore, and by keeping the liquid superficial velocity constant, the two-phase total pressure drop decreases with the increase of the gas superficial velocity.

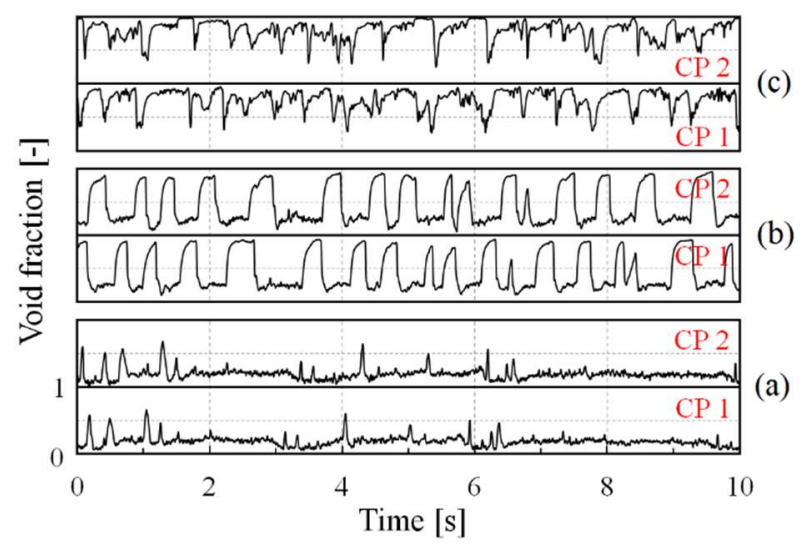

Figure 5: Temporal variation of the void fraction, (a), bubbly flow [Uls $\left.=0.80 \mathrm{~m} . \mathrm{s}^{-1}, \mathrm{Ugs}=0.10 \mathrm{~m} . \mathrm{s}^{-1}\right],(\mathrm{b})$, slug flow $[\mathrm{Uls}=0.40$ $\mathrm{m} . \mathrm{s}^{-1}, \mathrm{Ugs}=0.43 \mathrm{~m} \cdot \mathrm{s}^{-1}$ ], (c), churn flow [Uls $=0.21 \mathrm{~m} . \mathrm{s}^{-1}$, $\mathrm{Ugs}=3.01 \mathrm{~m} \cdot \mathrm{s}^{-1}$.
This finding can be clarified by the expansion of the gas in the gas-liquid flow due to gas superficial velocity increasing, which required less energy for the gas-liquid mixture to flow inside the pipe [14][19]. Besides the effect of the gas and liquid velocities, the way that the gas-liquid total pressure drop evolves in each flow pattern is not the same; the latter is very important for the bubbly flow and less when passing to the slug flow. The gas-liquid total pressure drop is nearly constant for the churn flow.

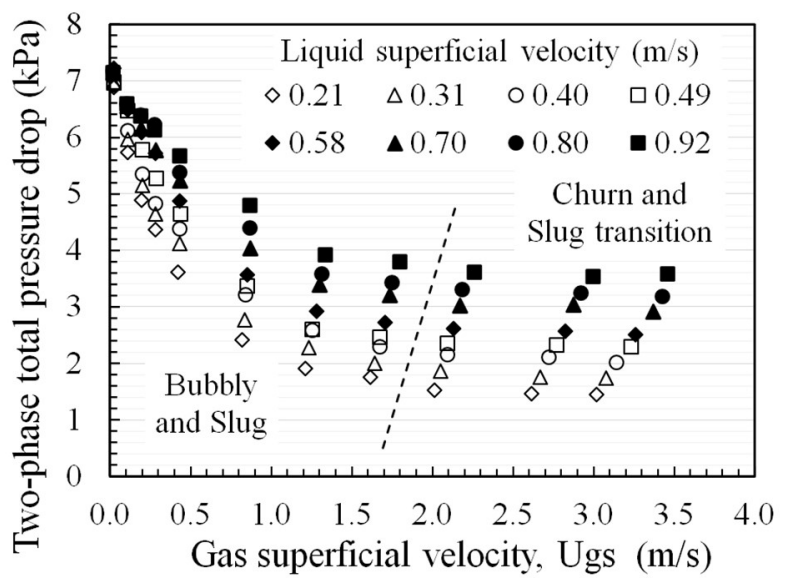

Figure 6: Total gas-liquid differential pressure vs. gas superficial velocity.

Figure 7 represents the calculated two-phase frictional pressure drop for different velocity combinations of the gas and the liquid. The corresponding data of the frictional pressure drop was derived from equation (3). From this figure and by maintaining a liquid superficial velocity constant, one can remark that the two-phase frictional pressure drop increases with the increase of the gas superficial velocity. The same behavior of the frictional pressure drop was noticed for a constant gas and variable liquid velocity. Besides the gas and liquid velocities' impact, the flow pattern was also found to affect the frictional two-phase pressure drop. The latter can be noticed from the different slopes of the frictional pressure drop, which characterizing each liquid superficial velocity. The sharpest slope was found in the churn flow. This may be caused by the turbulent effect of this kind of chaotic flow pattern, which enhances friction between phases and between the gasliquid mixture and the pipe inside wall.

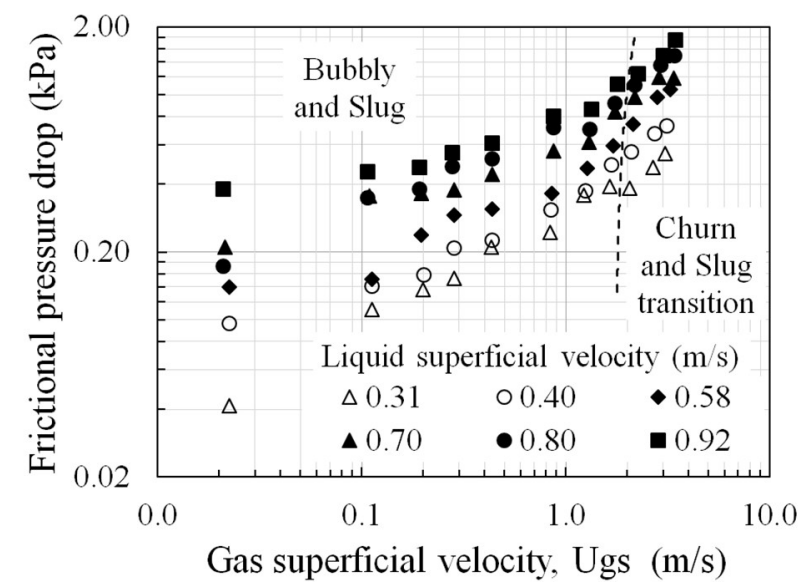

Figure 7: Gas-liquid frictional pressure drop vs. gas superficial velocity.

The measured single-phase (liquid) pressure drop was injected into equation (7) to find the experimental friction factor, $f$. 
The actual friction factor data and those calculated from It can be inferred from Figure 9 that, for $\varepsilon_{\mathrm{g}}<0.30$, the void Fanning correlation (Eq. (8)) and the experimental data of fraction predicted from differential pressure measurement Abbas [7] are represented in Figure 8. From this figure, one can agrees well with the measured one. For $\varepsilon_{\mathrm{g}}>0.30$, the deviation notice a good fit of the actual data to the experimental data of from the diagonal line increases with the void fraction. The Abbas and fanning correlation for the conditions of liquid deviation can reach $30 \%$ as the flow pattern approaches the superficial velocity, Uls, over $0.4 \mathrm{~ms}^{-1}$. For Uls, less than 0.4 slug/churn transition, which corresponding to the void fraction $\mathrm{ms}^{-1}$, we found some difference between the represented data of about 0.7 .

with a relatively good approach between the actual data and the Fanning correlation. This may be due to the accuracy of the differential pressure device when it is used in the low gas and liquid velocity conditions.

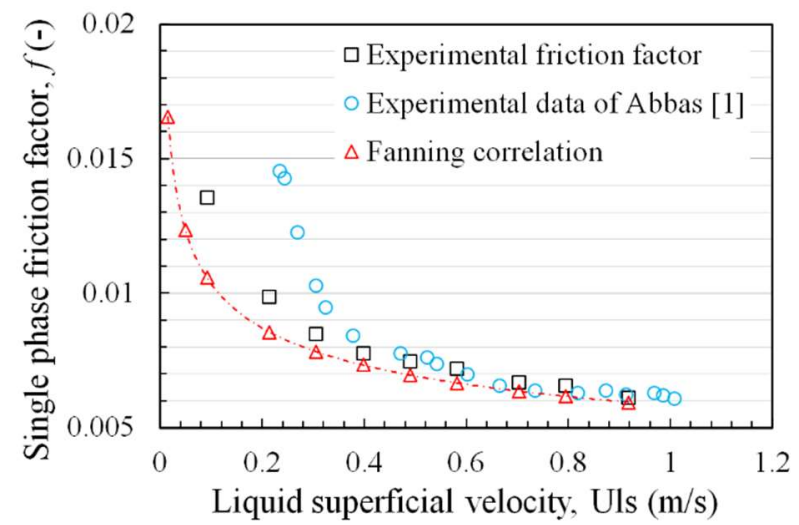

Fig. 8: Friction factor variation with water superficial velocity.

Figure 9 shows the variation of the measured gas-liquid pressure drop with the mean void fraction obtained from the conductance probes. One can see that the experimental data present a linear curve with a negligible effect of the various flow regimes. This finding confirms the linear relationship expressed in equation (5) between the measured two-phase pressure drop and the void fraction. In addition, the experimental data of the two-phase pressure drop increase with the increase of the void fraction. The latter can be obtained by increasing the gas's mass flow rate, i.e., the total two-phase flow rate, which induces in augmentation of both void fraction and the gas-liquid measured pressure drop.

\section{Calculated vs. Experimental Void Fraction}

Figure 10 exhibit the comparison between the calculated void fraction from the differential pressure transmitter (predicted void fraction) and the measured data using conductance probes.

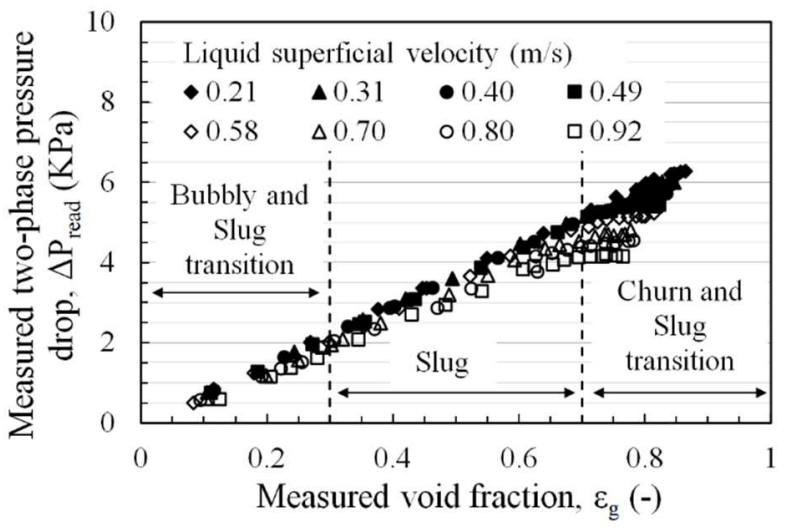

Figure 9: Experimental gas-liquid pressure drop vs. void fraction.

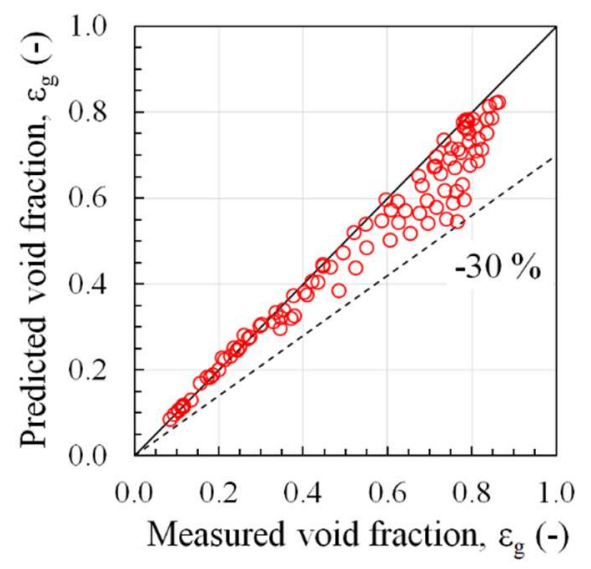

Figure 10: Comparison between Measured and predicted void fraction.

To quantify the deviation between the calculated void fraction from the gas-liquid pressure drop measurement and the measured void fraction from the conductance probes, two statistical parameters have been used. The first parameter is the root mean square deviation, RMS, and the second one is the mean relative absolute error, ABE, expressed in equations (9) to (11).

$$
\mathrm{RMS}=\sqrt{\frac{1}{\mathrm{n}} \sum_{\mathrm{i}=0}^{\mathrm{n}}\left[\frac{\varepsilon_{\mathrm{g}_{i, \text { calculated }}}-\varepsilon_{\mathrm{g}_{\mathrm{i}, \text { measured }}}}{\varepsilon_{\mathrm{g}_{\mathrm{i} \text {,measured }}}}\right]^{2}}
$$

$$
x_{\mathrm{i}}=\frac{\left|\varepsilon_{\mathrm{g}_{\mathrm{i}, \text { calculated }}}-\varepsilon_{\mathrm{g}_{\mathrm{i}, \text { measured }}}\right|}{\varepsilon_{\mathrm{g}_{\mathrm{i} \text {,measured }}}}
$$

$$
\mathrm{ABE}=\frac{1}{\mathrm{n}} \sum_{\mathrm{i}=0}^{\mathrm{n}} x_{\mathrm{i}}
$$

where $\varepsilon_{\mathrm{g}_{\mathrm{i} \text {,calculated }}}$ is the predicted void fraction from the twophase pressure measurement and $\varepsilon_{\mathrm{g}_{\mathrm{i} \text {,measured }}}$ is the measured void fraction from the conductance probes.

Table I, summarizes the two statistical parameters RMS and ABE obtained from the 121 experimental tests. From this table, one can see that the most accurate predicted data of the void fraction are those of the bubbly flow with an RMS and ABE of $3.63 \%$ and $2.57 \%$, respectively. As expected from figure 8 , The RMS and ABE increase considerably when passing from the bubbly to the slug flow with an RMS and ABE of $10.75 \%$ and $8.55 \%$, respectively, which are three times less accurate compared to the bubbly flow. For the churn flow, the results show the most deviated results with an RMS and ABE of $12.01 \%$ and $9.39 \%$, respectively. 
Table. I

RMS AND ABE (\%) OF VOID FRACTION FOR DIFFERENT FLOW REGIMES

\begin{tabular}{lcc}
\hline \hline & RMS & ABE \\
\hline Bubbly & & $2.57 \%$ \\
Slug & $3.63 \%$ & $8.55 \%$ \\
Churn & $10.75 \%$ & $9.39 \%$ \\
\hline \hline
\end{tabular}

E. Slip Ratio and Flow Pattern Effects

Figure 11 illustrates the impact of the flow pattern on the relative difference between the calculated and the experimental void fraction. Equally, in order to exhibit the slippage between the phases, the slip ratio has been added in the second axes. The latter can be calculated using the following expression.

$$
\mathrm{S}=\frac{\mathrm{U}_{\mathrm{G}}}{\mathrm{U}_{\mathrm{L}}}=\frac{\mathrm{U}_{\mathrm{GS}}\left(1-\varepsilon_{\mathrm{G}}\right)}{\mathrm{U}_{\mathrm{LS}} \varepsilon_{\mathrm{G}}}
$$

From this figure, the impact of the flow pattern is evident. For the bubbly flow $\left(\varepsilon_{\mathrm{g}}<0.30\right)$, the slip ratio between phases is around the unity indicating that the flow can be considered as homogeneous. The slip ratio increases beyond the unity when passing from bubbly to slug and considerably increases when reaching churn flow. A similar behavior of the slip ratio has been noticed for the relative difference error. The relation between these two parameters can be explained by the slip ratio's effect between the phases, which increases the frictional pressure drop between gas and liquid phases, i.e., the total frictional pressure drop [7]. The latter was not taken in the void fraction prediction, which in turn increases the error between the predicted and the measured void fraction.

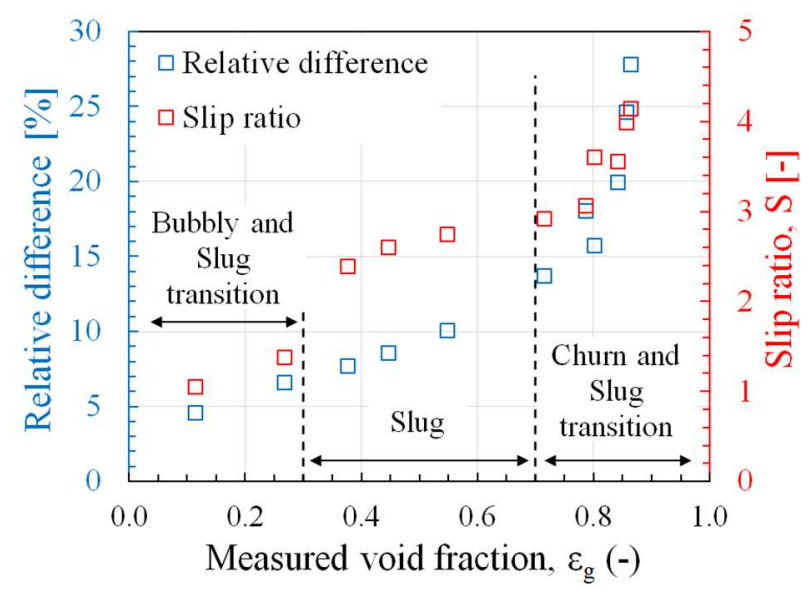

Figure 11: Impact of the two-phase flow pattern and slip ratio on void fraction predictions.

\section{CONCLUSION}

A differential pressure in a vertical ascending single and twophase flow has been measured. From the obtained pressure drop results, the void fraction was predicted from a model derived from energy conservation. The calculated void fraction data were compared to those measured experimentally from the conductance probe sensor. To evaluate the accuracy of the predicted void fraction from the energy conservation model, the statistical parameters RMS and ABE have been used.
The analysis of the two statistical parameter results showed that the bubbly flow pattern exhibits the most accurate results with RMS and ABE of $3.63 \%$ and $2.57 \%$, respectively. For the slug and the churn flow, $\varepsilon_{\mathrm{g}}>0.3$, the deviation between the theoretical and the experimental void fraction increases significantly. The results also showed that the frictional pressure drop between gas and liquid phases significantly affected the void fraction prediction accuracy. The latter cannot be neglected when the slip ratio between phases is beyond unity.

[1] Y. T. Shah, B. G. Kelkar, S. P. Godbole, and W. D. Deckwer, "Design parameters estimations for bubble column reactors," AIChE J., vol. 28 , no. 3, pp. 353-379, 1982, doi: 10.1002/aic.690280302.

[2] K. C. Ruthiya et al., "Detecting regime transitions in slurry bubble columns using pressure time series," AIChE J., vol. 51, no. 7, pp. 19511965, 2005, doi: 10.1002/aic.10474.

[3] G. Matsui, "Identification of flow regimes in vertical gas-liquid twophase flow using differential pressure fluctuations," Int. J. Multiph. Flow, vol. 10, no. 6, pp. 711-719, 1984, doi: 10.1016/03019322(84)90007-7.

[4] G. B. Wallis, One-dimensional two-phase flow. New York, 1969.

[5] C. Tang and T. J. Heindel, "Estimating gas holdup via pressure difference measurements in a cocurrent bubble column," Int. J. Multiph. Flow, vol. 32, no. 7, pp. 850-863, 2006, doi: 10.1016/j.ijmultiphaseflow.2006.02.008.

[6] A. Shafquet, I. Ismail, and M. N. Karsiti, "Study of void fraction measurement in a two phase flow by using differential pressure and Electrical Capacitance Tomography," in AMS2010: Asia Modelling Symposium 2010 - 4th International Conference on Mathematical Modelling and Computer Simulation, 2010, pp. 408-413, doi: 10.1109/AMS.2010.87.

[7] A. H. A. M. Hasan, "Measurement of a void fraction in bubbly gas-water two phase flows using differential pressure technique," Appl. Mech. Mater., vol. 152-154, pp. 1221-1226, 2012, doi: 10.4028/www.scientific.net/AMM.152-154.1221.

[8] J. Jia, A. Babatunde, and M. Wang, "This is a repository copy of Void Fraction Measurement of Gas-Liquid Two-Phase Flow from Differential Pressure. Void Fraction Measurement of Gas-Liquid Two-Phase Flow from Differential Pressure," Flow Meas. Instrum., vol. 41, pp. 75-80, 2015, doi: 10.1016/j.flowmeasinst.2014.10.010.

[9] S. Kara, B. G. Kelkar, Y. T. Shah, and N. L. Carr, "Hydrodynamics and Axial Mixing in a Three-phase Bubble Column," Ind. Eng. Chem. Process Des. Dev., vol. 21, no. 4, pp. 584-594, 1982.

[10] A. Zeghloul, H. Bouyahiaoui, A. Azzi, A. H. Hasan, and A. Al-sarkhi, "Experimental Investigation of the Vertical Upward Single- and TwoPhase Flow Pressure Drops Through Gate and Ball Valves," J. Fluids Eng., vol. 142, no. February, pp. 1-14, 2020, doi: 10.1115/1.4044833.

[11] A. Zeghloul, A. Messilem, N. Ghendour, A. Al-sarkhi, A. Azzi, and A. Hasan, "Theoretical study and experimental measurement of the gas liquid two-phase flow through a vertical Venturi meter," Proc IMechE Part C J Mech. Eng. Sci., vol. 0, no. 0, pp. 1-18, 2020, doi: 10.1177/0954406220947118.

[12] A. Zeghloul, A. Azzi, F. Saidj, A. Messilem, and B. J. Azzopardi, "Pressure Drop Through Orifices for Single- and Two-Phase Vertically Upward Flow - Implication for Metering," J. Fluids Eng. Trans. ASME, vol. 139, no. 3, pp. 1-12, 2017, doi: 10.1115/1.4034758.

[13] A. Zeghloul, A. Azzi, A. Hasan, and B. J. Azzopardi, "Behavior and pressure drop of an upwardly two-phase flow through multi-hole orifices," Proc. Inst. Mech. Eng. Part C J. Mech. Eng. Sci., vol. 232, no. 18, pp. 3281-3299, 2018, doi: 10.1177/0954406217736081.

[14] F. Saidj, A. Hasan, H. Bouyahiaoui, A. Zeghloul, and A. Azzi, "Experimental study of the characteristics of an upward two-phase slug flow in a vertical pipe," Prog. Nucl. Energy, vol. 108, no. June, pp. 428437, 2018, doi: 10.1016/j.pnucene.2018.07.001.

[15] A. Messilem, A. Azzi, A. Zeghloul, F. Saidj, H. Bouyahiaoui, and A. Alsarkhi, "Single- and two-phase pressure drop through vertical Venturis," Proc. Inst. Mech. Eng. Part C J. Mech. Eng. Sci., vol. 0, no. 0, pp. 1-11, 2020, doi: 10.1177/0954406220906424.

[16] H. Bouyahiaoui, A. Azzi, A. Zeghloul, A. H. Hasan, A. Al-Sarkhi, and M. Parsi, "Vertical upward and downward churn flow: Similarities and differences," J. Nat. Gas Sci. Eng., vol. 73, pp. 1-14, 2020, doi: 10.1016/j.jngse.2019.103080.

[17] G. Costigan and P. B. Whalley, "Slug flow regime identification from dynamic void fraction measurements in vertical air-water flows," Int. J. Multiph. Flow, vol. 23, no. 2, pp. 263-282, 1997, doi: 10.1016/s03019322(96)00050-x.

[18] O. Shoham, Mechanistic Modelling of Gas-Liquid Two-Phase Flow in Pipes. USA, 2006. 
[19] B. J. Azzopardi, H. K. Do, A. Azzi, and V. Hernandez Perez, "Characteristics of air/water slug flow in an intermediate diameter pipe," Exp. Therm. Fluid Sci., vol. 60, pp. 1-8, 2015, doi: 10.1016/j.expthermflusci.2014.08.004.

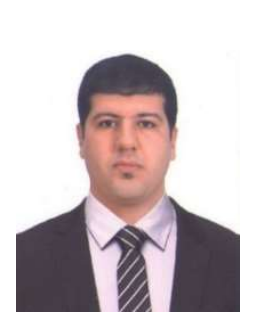

Ammar ZEGHLOUL received the Ph.D. degree in Mechanical Engineering Energy Mechanics option, from University of Sciences and Technology Houari Boumediene (USTHB), Algiers. Algeria. in 2016. He is currently a lecturer at the Department of preparatory cycle, Ecole Nationale Polytechnique (ENP) in Algiers, Algeria. and member of Laboratory of multiphase Transport and Porous Media, LTPMP-USTHB. His main research interests are in multiphase flow assurance which applications in oil and gas industry.

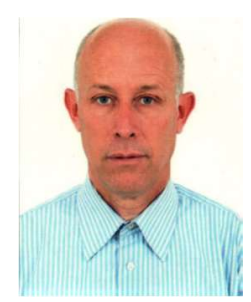

Abdelwahid Azzi is Professor and Director of research at the University of Sciences and Technology Houari Boumedien, Algiers (USTHB). He carried a large part of his Ph.D. thesis at the Technical University of Hamburg Harburg (TUHH), Germany. After the accomplishment of his $\mathrm{PhD}$, he was appointed at the same university (TUHH) for conducting researches on the sudden depressurization of twophase foaming flow from a chemical reactor. Then he re-joined the USTHB University where he led for several years the Twophase flow group in the Multiphase Flow and Porous Media Laboratory Flow and Porous Media Laboratory LTPMP (USTHB). During more than 30 years of research he was involved in several research activities most of them linked to multiphase flow. These activities find application in oil and gas production/transportation, design and safety process of chemical plants, wastewater treatment, thermal hydraulic plants and solar energy.

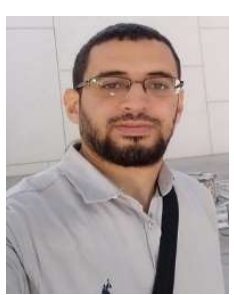

Nabil GHENDOUR received his M.Sc. degree in aeronautic engineering from the Institute of Aeronautics and Space Studies, Blida, Algeria, in 2015. He is currently pursuing the $\mathrm{Ph} . \mathrm{D}$. degree in mechanical engineering at the University of Sciences and Technology Houari Boumedien (USTHB), Algiers, Algeria. His research topics includes conductive sensing, sensor modeling and multiphase flow. He involved in several research works linked to multiphase flow measurement.

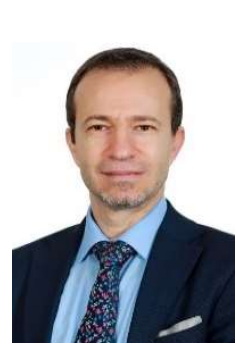

Abdallah Sofiane Berrouk was awarded a Ph.D. degree from The University of Manchester (UK) in the area of Computational Fluid Dynamics (CFD) and turbulence modelling. Before joining the Petroleum Institute in Abu Dhabi (PI) in October 2008, he worked as Senior Research/Teaching Associate at City University of Hong Kong. He has twelve years of university lecturing experience. He taught different courses in different departments both at the undergraduate and graduate levels. 